\title{
Desempenho da mistura de aveia preta e azevém em função da adubação orgânica e mineral ${ }^{1}$
}

\author{
Anderson Cesar Ramos Marques², Rodrigo Holz Krolow ${ }^{3}$,Edson Luis Rigodanzo , Laudenir Juciê Basso ${ }^{5}$, \\ Robson Antonio Botta ${ }^{6}$, Eloir Missio ${ }^{7}$
}

\begin{abstract}
RESUMO
Maximizar a eficiência dos sistemas de produção existentes, reduzindo a entrada de insumos externos e dos custos de produção é a lógica da agropecuária moderna. Baseado nisso, objetivou-se, com este trabalho, avaliar a influência das adubações orgânica e mineral no desenvolvimento e produção de massa seca (MS) do consórcio de aveia preta (Avena strigosa Schreb.) com azevém (Lolium multiflorum Lam.). O delineamento experimental utilizado foi o de blocos ao acaso, com quatro repetições, com os seguintes tratamentos: sem adubação; adubação mineral; adubação organomineral (50\% mineral e 50\% orgânica) e adubação orgânica. O experimento foi instalado em 15 de maio e conduzido até 28 de setembro de 2010. Foram realizadas três avaliações nesse período, por meio de cortes, para estimar a produção de MS e, semanalmente, verificaram-se o número de folhas, de afilhos e o comprimento da parte aérea das plantas de cada espécie. O efeito dos tratamentos sobre as variáveis número de afilhos, número de folhas e comprimento da parte aérea apresentou significância apenas nas primeiras avaliações. A produção de MS da cultura da aveia preta foi maior no primeiro corte, decaindo posteriormente, em função do ciclo precoce da espécie. O azevém teve elevada produção somente no último período, em função da característica de seu ciclo. Somando-se a MS obtida nos três períodos, concluiu-se que o dejeto de produção leiteira proporciona produção semelhante à favorecida pela adubação mineral. $\mathrm{O}$ mesmo comportamento foi observado para as características morfogênicas avaliadas, diferindo da testemunha.
\end{abstract}

Palavras-chave: Avena strigosa (Schreb.), dejeto bovino, Lolium multiflorum (Lam.), produção de forragem.

\section{ABSTRACT}

\section{Performance of the mixture of black oat and ryegrass as a function of organic and mineral fertilization}

Maximizing the efficiency of existing production systems and reducing the intake of external inputs and production costs is the principle of modern farming and livestock production. In this context, the aim of this study was to evaluate the influence of organic and mineral fertilization on dry mass (DM) development and production of the consortium of black oat (Avena strigosa Schreb.) and ryegrass (Lolium multiflorum Lam.). The experiment was arranged in a randomized block design, with four replications, with the following treatments: without fertilization, mineral fertilization only, organic and mineral fertilization (50\% mineral and 50\% organic) and organic fertilization only. The experiment was

\footnotetext{
Recebido para publicação em 16/08/2012 e aprovado em 14/06/2013.

${ }^{1}$ Trabalho de conclusão de curso do primeiro autor.

${ }^{2}$ Engenheiro-Agrônomo. Universidade Federal de Santa Maria, Rua Erly de Almeida Lima, 600/403, Camobi, 97105-120, Santa Maria, Rio Grande do Sul, Brasil. acrmarques@hotmail.com.br

${ }^{3}$ Engenheiro-Agrônomo, Doutor. Curso de Medicina Veterinária, Universidade Federal do Pampa, Campus Uruguaiana, BR 472, Km 592, Caixa Postal 118, 97500-970, Uruguaiana, Rio Grande do Sul, Brasil. rodrigokrolow@unipampa.edu.br (autor para correspondência).

${ }^{4}$ Engenheiro-Agrônomo. Universidade Federal do Pampa, Campus Itaqui, Rua Luiz Joaquim de Sá Britto, s/n, Promorar, 97650-000, Itaqui, Rio Grande do Sul, Brasil. edsonrigodanzo@hotmail.com

${ }^{5}$ Engenheiro-Agrônomo. Universidade Federal do Pampa, Campus Itaqui, Rua Luiz Joaquim de Sá Britto, s/n, Promorar, 97650-000, Itaqui, Rio Grande do Sul, Brasil. laudejb@hotmail.com

${ }^{6}$ Graduando em Agronomia. Universidade Federal do Pampa, Campus Itaqui, Rua Luiz Joaquim de Sá Britto, s/n, Promorar, 97650-000, Itaqui, Rio Grande do Sul, Brasil. robson_a.b@hotmail.com

${ }^{7}$ Engenheiro-Agrônomo, Doutor. Curso de Agronomia, Universidade Federal do Pampa, Campus Itaqui, Rua Luiz Joaquim de Sá Britto, s/n, Promorar, 97650-000, Itaqui, Rio Grande do Sul, Brasil. eloirmissio@gmail.com
}

Rev. Ceres, Viçosa, v. 61, n.1, p. 112-120, jan/fev, 2014 
conducted from May 15 to September 28, 2010. Three evaluations were performed in this period, using cuttings to estimate the DM production and recording the number of leaves, tillers and length of aerial part of plants of each species weekly. The effect of the treatments on the number of tillers, number of leaves and length of aerial part was significant only in the first evaluation. DM of black oat was higher in the first cutting and declined thereafter, due to its early cycle. Ryegrass obtained high production only in the last period, because of characteristics of its cycle. The total DM obtained in the three periods indicated that the dairy manure provides production similar to mineral fertilization. The same performance was obtained for the morphogenic characteristics evaluated, which differed from the control.

Key words: Avena strigosa (Schreb.), bovine waste, Lolium multiflorum (Lam.), forage production.

\section{INTRODUÇÃO}

A criação de bovinos em confinamento ou em semiconfinamento é considerada uma atividade de alto potencial poluidor, pois os dejetos gerados pelo sistema são lançados ao ambiente, sem tratamento adequado, podendo tornar-se agentes contaminantes de água e solo. Domingues \& Langoni (2001) ressaltam que, em geral, os níveis de dejetos podem ser mais preocupantes quando ocorre aumento da concentração de animais em uma área restrita. Esses autores definem dejeto como o conjunto de fezes, urina e água, dos bebedouros e da higienização, e os restos de ração e da alimentação fornecida.

Uma das alternativas para evitar a contaminação pelos dejetos seria seu uso na propriedade, como fonte de nutrientes para as culturas. Sua utilização pode reduzir a perda de solos, água e carbono orgânico (Silveira, 2009), além de ser uma forma econômica de fornecer nutrientes. Com a utilização, na propriedade, dos dejetos gerados pelo sistema de produção, proporciona-se o retorno de parte dos nutrientes extraídos do solo, como forma de nutrir as culturas destinadas à alimentação dos animais. $\mathrm{O}$ uso de esterco como forma de aporte nutricional às plantas pode trazer inúmeras vantagens ao sistema de produção, como melhorar as características do solo.

$\mathrm{Na}$ atividade leiteira, o uso de pastagens cultivadas é de suma importância, visto que garante um alimento de boa qualidade mais barato para o produtor. Em épocas de inverno ou de escassez de alimentos, torna-se uma grande fonte de nutrientes para a alimentação dos animais (Alvim, 2008). Entre as culturas mais utilizadas para o pastejo dos animais no período hibernal destacam-se o azevém (Lolium multiflorum Lam.), por apresentar facilidade de ressemeadura natural, grande resistência a doenças e capacidade de associação com outras gramíneas, e a aveia preta (Avena strigosa Schreb.) que apresenta crescimento mais rápido, resiste bem ao pisoteio e produz grande quantidade de massa verde para a alimentação animal (Bertolote, 2009).
Com base no trabalho realizado por Macedo (2006), sobre utilização de pastagens, apenas nos últimos anos intensificaram-se os estudos do comportamento de forrageiras e das formas de condução de pastagens, destacando-se que o desenvolvimento de uma boa estratégia de condução da pastagem, levando-se em conta as características da cultura que se tem como base, é de suma importância para obtenção de sucesso na atividade pecuária. A utilização da mistura da aveia preta e azevém, para o pastejo no período do inverno, proporciona produção de forragem elevada, que pode suprir as deficiências de alimentos comuns nessa época do ano, segundo relatado por Macari et al. (2006) e Bertolote (2009).

Nesse contexto, buscou-se, com este trabalho, avaliar a influência que a adubação orgânica - representada pelo dejeto de bovinos leiteiros - tem sobre características morfogênicas e produção de massa de matéria seca (MS) da mistura de aveia preta e azevém, comparada com a adubação mineral e a combinação dos dois tipos de fertilizantes.

\section{MATERIAL E MÉTODOS}

O experimento foi desenvolvido de maio a setembro de 2010, na área experimental da Universidade Federal do Pampa (Unipampa), situada no município de Itaqui, região da fronteira oeste do Rio Grande do Sul. A região é caracterizada pelo clima do tipo Cfa, subtropical temperado, segundo a classificação de Köppen-Geiger, com temperatura média mínima anual de $14,5^{\circ} \mathrm{C}$ e máxima de 25,3 ${ }^{\circ} \mathrm{C}$, com as menores temperaturas ocorrendo no mês de julho e as maiores em janeiro, sendo a média da precipitação anual de 1395,8 mm (Buriol et al., 2007). Durante o período de duração do experimento, o local onde se situava a área experimental teve como condições climáticas uma situação de normalidade no que se refere a temperaturas, acompanhando as médias históricas da região.

O solo da área é classificado como Plintossolo háplico (Embrapa, 2006). Para implantar o experimento, efetuaram- 
se subsolagem e gradagem. As análises física e química da área, realizadas conforme Tedesco et al. (1995) apresentaram os seguintes resultados: $\operatorname{argila}=18 \% ; \mathrm{pH}_{\text {(Água) }}=$ 5,$2 ; \mathrm{P}_{\text {(Mehlich-1) }}=3,6 \mathrm{mg} \mathrm{L}^{-1} ; \mathrm{K}=26 \mathrm{mg} \mathrm{L}^{-1}$; matéria orgânica $=1,6 \% ; \mathrm{Al}=0,6 \mathrm{cmol}_{\mathrm{c}} \mathrm{L}^{-1} ; \mathrm{Ca}=3,1 \mathrm{cmol}_{\mathrm{c}} \mathrm{L}^{-1} ; \mathrm{Mg}=1,2$ $\mathrm{cmol}_{\mathrm{c}} \mathrm{L}^{-1} ; \mathrm{H}+\mathrm{Al}=3,0 \mathrm{cmol}_{\mathrm{c}} \mathrm{L}^{-1}$.

O delineamento experimental utilizado foi o de blocos ao acaso, com quatro repetições. As culturas utilizadas no experimento foram a aveia preta, do cultivar denominado comum, e o azevém, de cultivar com a mesma denominação, semeados em consórcio, em parcelas de $6 \mathrm{~m}^{2}$ (3x2), e submetidos aos tratamentos denominados: TEST - sem adubação; ADMI - adubação mineral (300 kg ha-1 de NPK na fórmula 10-15-20); ADOM - adubação organomineral $50 \%$ adubo mineral e $50 \%$ dejeto líquido bovino - $(150 \mathrm{~kg}$ ha $^{-1}$ de NPK na fórmula 10-15-20 + 67.000 $\mathrm{L} \mathrm{ha}^{-1}$ de dejeto) e ADOR - adubação orgânica (135.000 L ha-1 de dejeto). As recomendações de adubação, tanto a mineral como a orgânica foram realizadas seguindo as recomendações da Comissão de Química e Fertilidade do Solo (CQFS, 2004), com base na análise de solo.

O cálculo da quantidade de dejeto necessária para fornecer as quantidades de nutrientes requeridas foi feito considerando-se sua densidade, para a qual se observou um valor de $1.016 \mathrm{~kg} \mathrm{~m}^{-3}$, com teores de: $\mathrm{N}=1,16 \mathrm{~kg} \mathrm{~m}^{-3}$; $\mathrm{P}_{2} \mathrm{O}_{5}=0,65 \mathrm{~kg} \mathrm{~m}^{-3} \mathrm{e} \mathrm{K}_{2} \mathrm{O}=1,09 \mathrm{~kg} \mathrm{~m}^{-3}$ (CQFS, 2004). Esse valor de densidade foi obtido pela utilização de um densímetro com escala de 1.000 a $1.060 \mathrm{~kg} \mathrm{~m}^{-3}$ para a medição, após a agitação por alguns minutos do material até perfeita homogeneização, e leituras repetidas de amostras com um recipiente adequado (copo de béquer 2000 $\mathrm{mL}$ ), no local do experimento. O material apresentava-se com pouca densidade, em função de ser obtido de um local de coleta da água de lavagem, das instalações onde os animais eram ordenhados. Primeiramente, determinouse a quantidade de dejeto a ser aplicado $\mathrm{em}^{3}$ com base na concentração do nutriente mais limitante no material, no caso, o fósforo, para suprir a quantidade requerida pela análise de solo $\left(80 \mathrm{~kg} \mathrm{ha}^{-1}\right)$, posteriormente, ajustouse essa quantidade para litros, sendo a determinação da adubação orgânica realizada no local do experimento, no momento da aplicação dos tratamentos.

O dejeto líquido bovino utilizado foi oriundo de uma propriedade de produção leiteira familiar, onde predominavam vacas da raça Holandesa, manejadas em pastagens e suplementadas com alimento concentrado energético e proteico.

A implantação do experimento ocorreu no dia 15 de maio e seu término deu-se em 28 de setembro de 2010, totalizando 136 dias. Para a semeadura, utilizaram-se $75 \mathrm{~kg}$ $\mathrm{ha}^{-1}$ de sementes viáveis de aveia preta e $30 \mathrm{~kg} \mathrm{ha}^{-1} \mathrm{de}$ azevém. Os fertilizantes foram aplicados na superfície do solo antes da semeadura e parcialmente incorporados na mesma operação de incorporação das sementes das forrageiras, com a utilização de um rastilho.

Durante o ciclo de desenvolvimento das espécies, foram realizados três cortes para quantificação de massa de matéria seca produzida (MS), utilizando dois quadros de amostragem de $0,25 \mathrm{~m}^{2}$ por parcela, aos 44, 95 e 133 dias após a semeadura, constituindo-se assim três períodos de avaliação. Os cortes foram realizados com tesoura, a 7 $\mathrm{cm}$ de altura do solo, aproximadamente, quando constatada a altura média nas parcelas próxima a $30 \mathrm{~cm}$. O material coletado nos cortes foi levado para o laboratório, onde se realizou a separação das plantas de aveia preta e de azevém, com posterior determinação da massa de matéria verde. Em sacos de papel, o material foi colocado em estufa, com circulação de ar forçada, a $65^{\circ} \mathrm{C}$ por 72 horas, até massa constante, e pesado para determinação da MS, para cada período e espécie. A taxa de acúmulo diário (TAD) foi calculada, dividindo-se a MS obtida pelo número de dias de cada período. Somando-se a MS dos três períodos e de cada espécie obteve-se a massa de matéria seca total (MST), produzida no experimento. Após cada avaliação de MS, todas as parcelas eram cortadas a $7 \mathrm{~cm}$ de altura, e a biomassa era retirada das parcelas.

Para a avaliação das variáveis número de afilhos (NA), número de folhas (NF), e comprimento da parte aérea (CPA), foram marcadas cinco plantas por espécie, em cada parcela, as quais tiveram seu desenvolvimento acompanhado semanalmente. A contagem do NA e do NF foi realizada, manualmente, nas plantas marcadas. Para a avaliação da variável CPA, as plantas foram medidas com régua graduada em $\mathrm{cm}$, da base do solo até a ponta da última folha estendida. Para a comparação de médias, foram utilizados os valores obtidos na última avaliação antes de cada corte.

Após realizada toda a coleta de dados, os resultados foram submetidos à análise de variância e teste $\mathrm{F}$, para verificar a ocorrência de diferenças entre os tratamentos; havendo diferença, foi realizado o teste de Scott-Knott, a $5 \%$ de probabilidade. A análise estatística foi feita empregando-se o programa ASSISTAT (Silva \& Azevedo, 2006).

\section{RESULTADOS E DISCUSSÃO}

As adubações orgânica e mineral influenciaram positivamente, e de modo significativo, a produção de MS (Tabela 1), demonstrando sua importância principalmente nos estádios iniciais das culturas. No primeiro período, a produção de MS da aveia preta sem adubo chegou a apenas $29 \%$ do obtido pelos demais tratamentos, com o azevém apresentando comportamento semelhante, com apenas $18,9 \%$ da média dos tratamentos adubados.

A adubação mineral geralmente tende a fazer com que as culturas apresentem esses comportamentos, pois o 
fornecimento de parte dos nutrientes ocorre de forma imediata, no início do desenvolvimento das culturas. Berté et al. (2010) comprovaram que a liberação de N é mais rápida na adubação mineral do que em materiais orgânicos sólidos, quando comparou adubações orgânicas e minerais na cultura do milho (Zea mays L.). Os autores salientam que, para ocorrer a liberação de nutrientes, no caso da adubação orgânica sólida, existe a necessidade de mineralização desses compostos, só após o que, então, haverá a disponibilidade para as culturas. No entanto, conforme Tabela 1, pode-se observar que os tratamentos com dejetos bovinos, produziram quantidades de MS semelhantes às do ADMI e do ADOR, na cultura da aveia preta. A causa, para isso, seria o estado físico do dejeto, pois estercos sólidos apresentam alto teor de lignina, além de uma menor quantidade de nutrientes na forma mineral, ou seja, a liberação destes para as plantas dar-se-ia de uma forma mais complexa, ao contrário dos dejetos de consistência mais líquida, característica do dejeto utilizado neste trabalho, que apresentam maior quantidade de nutrientes na forma mineral, considerando-se que a adição de MS seria igual, apenas com diferenças no seu estado (CQFS, 2004), ou seja, dejetos líquidos apresentam maior quantidade de nutrientes prontamente disponíveis para as plantas.

Outro importante fator que levou à grande produção da aveia preta no início do seu desenvolvimento, e seu posterior declínio de produção, foi a própria característica genética, que leva à uma grande taxa de crescimento nos primeiros 70 dias após a emergência (Steiner et al.,
2009). Com relação ao segundo período da cultura da aveia preta, observou-se que os tratamentos que receberam adubação apresentaram redução significativa em suas produções, com diferenças de até $1000 \mathrm{~kg} \mathrm{ha}^{-1}$, se comparados com a da testemunha. Essa diferença de produção de MS deve-se ao corte e, também, ao próprio efeito da fertilização no crescimento das plantas. Na altura de corte das plantas adubadas, foram atingidos apenas colmos, pois elas apresentavam porte elevado, ocasionando, em alguns casos, a morte de afilhos. Fato semelhante foi relatado por Roso et al. (2000), quando submeteram o consórcio de centeio (Secale cereale L.) e azevém ao pastejo animal, observando o corte dos pontos de crescimento e sua senescência, sendo necessário aguardar o desenvolvimento de novos afilhos, com consequente retardo na produção.

Desta forma, para que as plantas de aveia preta voltassem a produzir folhas, houve a necessidade da produção de novos afilhos, fato este que não ocorreu nas plantas da testemunha, que, por apresentarem porte reduzido, acumularam MS com a produção de novas folhas, enquanto, no mesmo período, nos demais tratamentos, as plantas direcionaram seus nutrientes para emissão de novos afilhos. Desse modo, a testemunha superou os demais tratamentos, significativamente. Esse efeito perdurou durante o restante do ciclo, pois, no terceiro período, novamente, a testemunha superou os demais tratamentos, evidenciando o fato de não ser suficiente o teor residual de ambas as adubações para a geração de novos afilhos e folhas. Pode-se justificar o observado, pela dis-

Tabela 1. Produção de matéria seca de aveia preta e azevém consorciados ao longo de três cortes, nos diferentes tratamentos: testemunha (TEST), adubação mineral (ADMI), adubação organomineral (ADOM) e adubação orgânica (ADOR)

\begin{tabular}{|c|c|c|c|c|c|c|c|}
\hline \multirow{3}{*}{ Trat. } & \multicolumn{3}{|c|}{ Aveia preta } & \multicolumn{3}{|c|}{ Azevém } & \multirow{3}{*}{ MS Total } \\
\hline & $1^{\circ}$ Per. & $2^{\circ}$ Per. & $3^{\circ}$ Per. & $1^{\circ}$ Per. & $2^{\circ}$ Per. & $3^{\circ}$ Per. & \\
\hline & \multicolumn{6}{|c|}{ Massa seca de forragem $\left(\mathrm{kg} \mathrm{ha}^{-1}\right)$} & \\
\hline TEST & $308 \mathrm{~b}$ & $1185 \mathrm{a}$ & $200 \mathrm{a}$ & $154 \mathrm{~b}$ & $748 \mathrm{a}$ & $1218 \mathrm{~b}$ & $3816 b$ \\
\hline ADMI & $1019 \mathrm{a}$ & $209 \mathrm{~b}$ & $42 \mathrm{~b}$ & $907 \mathrm{a}$ & $1331 \mathrm{a}$ & $2463 \mathrm{a}$ & $6572 \mathrm{a}$ \\
\hline ADOM & $992 \mathrm{a}$ & $323 \mathrm{~b}$ & $77 \mathrm{~b}$ & $679 a$ & $1425 \mathrm{a}$ & $3068 \mathrm{a}$ & $6567 \mathrm{a}$ \\
\hline \multirow[t]{2}{*}{ ADOR } & $1147 \mathrm{a}$ & $166 \mathrm{~b}$ & $41 \mathrm{~b}$ & $856 \mathrm{a}$ & $1707 \mathrm{a}$ & $2921 \mathrm{a}$ & 6839 a \\
\hline & \multicolumn{7}{|c|}{ Taxa de acúmulo (kg ha dia ${ }^{-1}$ de MS) } \\
\hline TEST & $5,14 \mathrm{~b}$ & 23,24 a & $5,15 \mathrm{a}$ & $2,58 \mathrm{~b}$ & $14,67 \mathrm{~b}$ & $31,23 \mathrm{~b}$ & \\
\hline ADMI & 16,99 a & $4,10 \mathrm{~b}$ & $1,07 \mathrm{~b}$ & 15,12 a & 37,87 a & 63,15 a & \\
\hline ADOM & $16,54 \mathrm{a}$ & $6,33 \mathrm{~b}$ & $1,97 \mathrm{~b}$ & $11,32 \mathrm{a}$ & $27,95 \mathrm{a}$ & $78,68 \mathrm{a}$ & \\
\hline \multirow[t]{3}{*}{ ADOR } & $19,12 \mathrm{a}$ & $3,26 \mathrm{~b}$ & $1,06 \mathrm{~b}$ & $14,26 \mathrm{a}$ & $33,47 \mathrm{a}$ & 74,89 a & \\
\hline & \multicolumn{6}{|c|}{ Taxa de acúmulo total de aveia preta+azevém $\left(\mathrm{kg} \mathrm{ha} \mathrm{dia}^{-1}\right.$ de MS) } & \\
\hline & \multicolumn{2}{|c|}{$\mathbf{1}^{\circ}$ Período } & \multicolumn{2}{|c|}{$2^{\circ}$ Período } & \multicolumn{2}{|c|}{$3^{\circ}$ Período } & \\
\hline TEST & \multicolumn{2}{|c|}{$7,71 \mathrm{~b}$} & \multicolumn{2}{|c|}{37,91 a } & \multicolumn{2}{|c|}{$36,38 \mathrm{~b}$} & \\
\hline ADMI & \multicolumn{2}{|c|}{$32,11 \mathrm{a}$} & \multicolumn{2}{|c|}{$41,97 \mathrm{a}$} & \multicolumn{2}{|c|}{$64,23 \mathrm{a}$} & \\
\hline ADOM & \multicolumn{2}{|c|}{$27,86 \mathrm{a}$} & \multicolumn{2}{|c|}{$34,29 \mathrm{a}$} & \multicolumn{2}{|c|}{80,66 a } & \\
\hline ADOR & \multicolumn{2}{|c|}{33,38 a } & \multicolumn{2}{|c|}{$36,73 \mathrm{a}$} & \multicolumn{2}{|c|}{$75,96 \mathrm{a}$} & \\
\hline
\end{tabular}

Médias seguidas pela mesma letra na coluna não diferem entre si pelo teste Scott-Knott $(\mathrm{P}>0,05)$. 
ponibilidade de nutrientes da adubação orgânica, que, a longo prazo, durante o ciclo da aveia preta, não apresentou diferença, em comparação com a disponibilidade no caso da ADMI, tendo esta, provavelmente, disponibilizado a maioria dos seus nutrientes, que estariam na forma mineral, no início do desenvolvimento das culturas.

Na cultura do azevém, o primeiro período não influenciou o desenvolvimento das plantas, por causa do ciclo mais tardio da cultura (Alvim, 2008). Com as plantas apresentando um porte inferior, não ocorreu o corte de meristemas a ponto de prejudicar a desenvolvimento posterior das plantas. No segundo período, mesmo não ocorrendo diferença estatística entre os quatro tratamentos, por estar o ciclo da cultura em um estádio intermediário de desenvolvimento, pode-se notar que ocorreu aumento de produção nos tratamentos que receberam adubação, aumento este que, para o terceiro período, apresentou significância, com acréscimos de 85,115 e $71 \%$ para ADMI, ADOM e ADOR, respectivamente.

Observando a Tabela 1, pode-se dizer que ao longo do período de consórcio, a produção de MS foi adequada e governada pelas características de cada espécie, como se esperava. A característica de precocidade da aveia preta fez com que sua produção de MS se sobrepusesse à do azevém, no início do ciclo, acontecendo o inverso, a partir do primeiro corte, por causa do azevém ter hábito de crescimento mais tardio. Em geral, no início do desenvolvimento de uma pastagem consorciada de aveia preta e azevém, existe uma dominância da aveia preta, com um percentual de 73\%, em média (Assmann et al., 2004), por causa de uma maior produção de colmos e folhas, ocupando os extratos mais altos do dossel, que tendem a suprimir o azevém.

Com o aumento das temperaturas na primavera, as taxas de acumulação de MS, em forma de folhas, por parte da aveia preta, tendem a diminuir, enquanto as do azevém aumentam e, no final do ciclo da pastagem, pode-se dizer que o azevém participa com aproximadamente $82 \%$ da massa seca total produzida (Aguinaga et al., 2008). Segundo avaliação realizada por Roso et al. (2000), as pastagens consorciadas dessas duas culturas começam com percentuais de 83 e $16 \%$, para aveia preta e azevém, respectivamente, e terminam, se conduzidas até novembro, com 54,6\% de azevém. Com base nas quantidades de MS médias produzidas pelos tratamentos ADMI, ADOM e ADOR, neste trabalho, obtiveram-se valores iniciais de 56,37 e 43,62\%, para aveia preta e azevém, respectivamente, enquanto, no terceiro período, a aveia preta produziu apenas $1,84 \%$, sendo o azevém responsável por $98,18 \%$ do total de MS produzida.

Realizando-se uma análise da MS seca gerada em todo o ciclo, percebe-se que os tratamentos não diferiram entre si, pois o somatório da produção de massa pelas duas espécies, durante todo o ciclo, apresentou valores próximos de $6500 \mathrm{~kg} \mathrm{ha}^{-1}$, para ADMI, ADOM e ADOR, enquanto a testemunha, por não receber aporte de nutrientes via adubação, apresentou resultado inferior, diferindo dos demais tratamentos (Tabela 1).

$\mathrm{O}$ fato de não ocorrer diferença estatística entre os resultados das diferentes formas de adubação pode levar a dizer que o método utilizado para a definição da quantidade de fertilizante orgânico foi adequada, bem como a atribuir a mesma influência, por parte dos tratamentos, na produção de MS, em ambas as espécies. As quantidades de MS encontradas neste trabalho estão próximas das alcançadas por Frizzo et al. (2003), que obtiveram em torno de $7200 \mathrm{~kg} \mathrm{ha}^{-1}$, e acima das encontradas por Macari et al. (2006), que, utilizando azevém em consórcio com aveia preta "Comum" e o cultivar IAPAR 61, obtiveram valores de 5083,3 e 4743,1 $\mathrm{kg} \mathrm{ha}^{-1}$, respectivamente.

Os valores da TAD, no primeiro período (Tabela 1), indicam o incremento de MS da parte aérea pela influência da adubação, com a testemunha apresentando um valor de $29 \%$ do obtido, em média, pelos tratamentos fertilizados, para a cultura da aveia preta, e 19\%, para a do azevém. No segundo período observou-se TAD inferior, por parte dos tratamentos adubados, em função dos cortes realizados na altura dos colmos, abaixo dos pontos de crescimento, o que também afetou o NA (Tabela 2).

Em geral, a TAD foi crescente, durante os períodos, com variações na sua composição. Inicialmente, de 53 a $66 \%$ desta foi composta por aveia preta, já, no terceiro período, de 85 a $98,5 \%$ da TAD total foi composta por MS de azevém. Os valores de TAD total, obtidos neste trabalho no período inicial estão próximos dos 38,5 a 41,7 kg ha $\mathrm{dia}^{-1}$ de MS médios, obtidos por Macari et al. (2006) em pastagem adubada com fertilizante mineral. Pilau et al. (2004), em pastagem de aveia preta e azevém, com pastejo de animais, obtiveram uma taxa de acúmulo média de 40 $\mathrm{kg}$ ha $\mathrm{dia}^{-1}$, valor abaixo do obtido ao final deste estudo (Tabela1), que ficou próximo dos encontrados por Steiner et al. (2009) para os tratamentos com adubação, quando avaliaram o efeito da aplicação de fertilizantes orgânicos e minerais sobre o crescimento e produção de matéria seca de aveia preta, com produções de mais de $80 \mathrm{~kg}$ ha dia- ${ }^{-1}$, utilizando dejeto líquido bovino.

A influência das adubações orgânica e mineral sobre a produção de afilhos das plantas de aveia preta, no início do desenvolvimento da cultura, expressou-se de forma satisfatória, produzindo até dois afilhos a mais do que a testemunha, decorrente do fornecimento de nutrientes por parte da adubação de base (Tabela 2). O NA do segundo para o terceiro período, da aveia preta, apresentou uma redução drástica, possivelmente por causa do final do ciclo da cultura, com as plantas passando a translocar os nutrientes para a formação de órgãos reprodutivos e não 
mais para a formação de afilhos. Também se deve à condição de uso das plantas de aveia preta, cujos cortes, por exemplo, geram a remoção repetida de colmos e folhas, fator que, aliado ao final de seu ciclo, tende a diminuir o número de afilhos das plantas, pois a capacidade de reposição por parte da planta está relacionada com o estádio de desenvolvimento e com o ciclo da cultura. Quanto mais tardia for a remoção, mais difícil será sua recuperação (Mullahey et al., 1991). Sendo os afilhos considerados os componentes mais importantes para produção de gramíneas forrageiras (Freitas, 2000), é esperado que, quando ocorra sua diminuição, também exista diminuição na produção de MS.

As culturas do azevém e da aveia preta mostraram, no início do ciclo, grande potencial de resposta ao efeito da adubação, pois a testemunha apresentou resultado inferior, diferindo daquele dos demais tratamentos, nos dois primeiros períodos. Ao final do estudo, observou-se a ausência de diferença estatística para o NA, principalmente, decorrente do final do ciclo da cultura, quando esta estaria já direcionando os nutrientes para a geração de estruturas reprodutivas, mas, também, possivelmente, pelo esgotamento dos nutrientes provenientes da adubação para as plantas (Tabela 2).

O uso das gramíneas forrageiras para o pastejo é uma forma de suprir as demandas por alimentos requeridos pelos animais. No entanto, a utilização de adubação em pastagens se faz necessária, pois, conforme os resultados deste experimento (Tabelas 1 e 2), mesmo as parcelas adubadas, ao final do estudo, apresentaram redução da produção de MS, tanto pela remoção de biomassa aérea, por cortes e consequente senescência de alguns colmos, quanto pela redução significativa no número de afilhos.

Freitas (2000) ressalta que o aparecimento de afilhos, em gramíneas forrageiras, acontece, no início do ciclo, de forma intensa, sendo muito importante para o estabeleci- mento da cultura. A dinâmica de perfilhamento inicia-se quando a planta atinge de três a cinco folhas. No entanto, com o passar do tempo, este aparecimento deixa de ser intenso, visto que, no final do ciclo da cultura ocorre apenas elongação dos afilhos já existentes e concentração de massa, por parte deles. Por este motivo, é muito importante manejar de forma racional a pastagem, para que não se comprometa a produção de MS.

Cabe salientar, segundo Valério et al. (2009), que, muitas vezes, o número de afilhos não pode ser atribuído somente às questões externas, como luz, adubação ou pastejo. Em alguns casos, mesmo sob condições ótimas, não se tem uma resposta satisfatória, com relação à quantidade de afilhos, sendo a característica genética da planta de suma importância para isto. Neste contexto, o uso de sementes de qualidade para a formação das pastagens faz que se tenha uma resposta maior na produção de afilhos, que, por sua vez, carregam no seu genótipo excelentes características de produção (Ohlson et al., 2008), fazendo que, mesmo sob condições de estresse nutricional, ou climático, apresente-se uma produção adequada de afilhos. Neste sentido, fazem-se necessários mais conhecimentos sobre a influência dos genes nas características número de afilhos e respostas morfológicas e fisiológicas das plantas à variação ambiental, para poder-se entender, de forma mais clara, como deve ser o manejo, em diferentes condições de uso, das espécies gramíneas.

O NF por planta é uma característica morfogênica de extrema importância, pois influencia diretamente o comportamento dos animais sob pastejo. Variáveis como tempo de pastejo, ritmo de bocadas e tamanho de bocada são altamente influenciadas pela quantidade de folhas presentes na área destinada ao pastejo (Valério et al., 2009). Assim, avaliando a influência que as diferentes adubações teriam sobre o NF de plantas de aveia preta e azevém, observou-se que, para as plantas de aveia preta, pelo fato

Tabela 2. Dados médios de número de afilhos e folhas de plantas de aveia preta e azevém cultivadas em consórcio, avaliadas em três períodos nos diferentes tratamentos de adubação, testemunha (TEST), adubação mineral (ADMI), adubação organomineral (ADOM) e adubação orgânica (ADOR)

\begin{tabular}{|c|c|c|c|c|c|c|}
\hline \multirow{3}{*}{ Tratamentos } & \multicolumn{3}{|c|}{ Aveia preta } & \multicolumn{3}{|c|}{ Azevém } \\
\hline & $1^{\circ}$ Período & $2^{\circ}$ Período & $3^{\circ}$ Período & $1^{0}$ Período & $2^{\circ}$ Período & $3^{\circ}$ Período \\
\hline & \multicolumn{6}{|c|}{ Afilhos (n\%/planta) } \\
\hline TEST & $1,9 \mathrm{~b}$ & $3,7 \mathrm{a}$ & $2,1 \mathrm{a}$ & $3,3 \mathrm{~b}$ & $4,1 \mathrm{~b}$ & $1,4 \mathrm{a}$ \\
\hline ADMI & $4,3 \mathrm{a}$ & $5,2 \mathrm{a}$ & $1,6 \mathrm{a}$ & $5,1 \mathrm{a}$ & $5,1 \mathrm{a}$ & $1,8 \mathrm{a}$ \\
\hline ADOM & $4,0 \mathrm{a}$ & $5,5 \mathrm{a}$ & $2,1 \mathrm{a}$ & $5,7 \mathrm{a}$ & $5,9 \mathrm{a}$ & $2,4 \mathrm{a}$ \\
\hline \multirow[t]{2}{*}{ ADOR } & $4,2 \mathrm{a}$ & $5,5 \mathrm{a}$ & $2,4 \mathrm{a}$ & $5,4 \mathrm{a}$ & $6,0 \mathrm{a}$ & $1,1 \mathrm{a}$ \\
\hline & \multicolumn{6}{|c|}{ Folhas (n\%/planta) } \\
\hline TEST & $7,0 \mathrm{~b}$ & $10,6 \mathrm{a}$ & $3,8 \mathrm{a}$ & $10,0 \mathrm{~b}$ & $11,8 \mathrm{a}$ & $2,5 \mathrm{a}$ \\
\hline ADMI & $12,4 \mathrm{a}$ & $12,0 \mathrm{a}$ & $3,3 \mathrm{a}$ & $15,8 \mathrm{a}$ & $12,6 \mathrm{a}$ & $3,6 \mathrm{a}$ \\
\hline ADOM & $12,6 \mathrm{a}$ & $13,4 \mathrm{a}$ & $6,1 \mathrm{a}$ & $19,8 \mathrm{a}$ & $13,7 \mathrm{a}$ & $5,1 \mathrm{a}$ \\
\hline ADOR & $13,6 \mathrm{a}$ & $12,9 \mathrm{a}$ & $6,2 \mathrm{a}$ & $17,8 \mathrm{a}$ & $10,9 \mathrm{a}$ & $2,6 \mathrm{a}$ \\
\hline
\end{tabular}

Médias seguidas pela mesma letra na coluna não diferem entre si pelo teste Scott-Knott $(P>0,05)$. 
de apresentarem rápido crescimento inicial e boas condições de fertilidade, ADMI, ADOM e ADOR apresentaram os melhores resultados, no primeiro período (Tabela 2). Esse efeito não foi verificado nos dois períodos posteriores, nos quais não se observaram diferenças estatísticas, e isto se deve à influência do corte, que diminui a quantidade de folhas. O efeito dos cortes sobre o desenvolvimento das plantas fica claro no terceiro período, em que, aliados ao final do ciclo da cultura, o aumento das temperaturas da primavera e o esgotamento do aporte nutricional (Rocha et al., 2007) influenciaram na redução de pelo menos metade do NF das plantas de aveia preta (Tabela 2).

$\mathrm{O}$ azevém mostrou comportamento semelhante ao da aveia preta, pois ADMI, ADOM e ADOR diferiram estatisticamente da testemunha apenas no primeiro período, com a adubação tendo influência sobre o número de folhas, inicialmente (Tabela 2). Segundo Freitas (2000), o surgimento e o número de folhas por afilhos depende do genótipo da espécie e do cultivar, mas salienta que a desfolha severa pode causar, em alguns casos, a morte de afilhos e, consequentemente, a morte da planta. Por essas razões, faz-se necessário um manejo adequado, com adubação e controle de pastejo, mesmo quando se usa material genético de qualidade.

Outra relação muito importante, que a quantidade de folhas pode apresentar com o desenvolvimento da planta, diz respeito à quantidade de luz que é interceptada pela planta. Uma grande área foliar tende a capturar uma grande quantidade de luz, ocasionando uma maior produção de fotoassimilados, devida à grande área fotossintética ativa (Valério et al., 2009). Desta forma, a influência significativa que as adubações testadas tiveram sobre a produção de biomassa, neste estudo, está relacionada com a maior disponibilidade de nutrientes, que possibilitou maior produção de folhas, aumentando a quantidade de luz captada pela maior área foliar resultante. Sendo a quantidade de folhas afetada por fatores abióticos, como luz, disponibilidades hídricas e nutricionais (Taiz \& Zeiger, 2009); essa última relação foi verificada neste trabalho, pois as plantas que receberam um aporte nutricional apresentaram maior NF (Tabela 2).

Avaliando-se a influência dos tratamentos no CPA das plantas de aveia preta (Tabela 3), percebe-se que o efeito da fertilização, na primeira avaliação, possibilitou um melhor desempenho - evidente, quando se observa a Figura 1 -, com os tratamentos adubados apresentando, em média, 32,2 $\mathrm{cm}$ a mais que a testemunha, e apresentando comportamento similar ao observado para as variáveis NA e NF (Tabela 2). No entanto, esse efeito não foi verificado nos dois períodos seguintes e deve-se ao corte realizado, que removeu grande parte dos pontos de crescimento, ocasionando a morte de afilhos e folhas, sendo necessária a geração de novas estruturas vegetativas, ao passo que as plantas da testemunha, pelo porte reduzido, não sofreram com a remoção. Outra possível causa de não se verificar diferença estatística para o comprimento das plantas da cultura da aveia preta é a questão da constituição genética, pois esta também entra como determinante do porte das plantas.

As plantas de azevém apresentaram CPA maiores para ADMI, ADOM e ADOR, e, assim como para as demais variáveis analisadas, na primeira avaliação, as plantas dos tratamentos que receberam adubação apresentaram diferença estatística, quando comparados seus resultados com os da testemunha. Conforme mostra a Figura 1, os tratamentos com adubação apresentaram uma diferença média superior a $22 \mathrm{~cm}$, em relação à testemunha, por causa do fornecimento de nutrientes por parte da adubação, na primeira avaliação; já, para a segunda avaliação, essa diferença reduziu-se para $12 \mathrm{~cm}$. Diferentemente da aveia preta, que apresenta rápido crescimento inicial e na segunda avaliação já não apresentava mais diferença na altura, o azevém, de ciclo mais tardio (Piazzetta et al., 2009) ainda se encontrava em fase de crescimento, com aumento do CPA, com a testemunha apresentando os menores valores (Tabela 3).

No terceiro período para a cultura do azevém, pela severidade dos cortes realizados, pela fase reprodutiva na qual se encontrava e pela diminuição do fornecimento de nutrientes por parte da adubação, não se verificaram diferenças significativas para a variável CPA entre os tratamentos, podendo-se observar, na Figura 1, que as espécies apresentavam alturas muito próximas. Essa variável é de grande importância para as plantas forrageiras e, muitas vezes, em condições de pastejo intenso, torna-se mais importante que a própria densidade de plantas (Piazzetta, 2007).

As diferenças de CPA são influenciadas diretamente pelas TCDs, pelo que ADOM proporcionou taxas de até 1,9 e 1,24 $\mathrm{cm} \mathrm{dia}^{-1}$ (Tabela 3), no primeiro período, para aveia preta e azevém, respectivamente. Assim, em 15 dias essas plantas passaram de 32 e $21 \mathrm{~cm}$ para 60,5 e 39,6 cm, respectivamente (Figura 1), cujas TCDs, obtidas pelo método utilizado, consideram, além do crescimento das folhas, a elongação de colmos. Pode-se observar, ainda, durante o terceiro período, a não ocorrência de significância entre os tratamentos, possivelmente por causa do final do ciclo das duas culturas e de diminuição da disponibilidade de nutrientes, ficando evidente, quando se observa o comportamento do crescimento das espécies, na Figura 1. De forma geral, as TCDs de ambas as culturas ficaram em torno de um centímetro ao dia, quando estas não foram submetidas ao distúrbio, diferentemente do ocorrido no segundo período, quando as plantas foram afetadas pelo corte dos colmos, diminuindo, assim, a TCD, e retardando o crescimento. 
Tabela 3. Comprimento da parte aérea e taxa de crescimento das plantas de aveia preta e azevém cultivadas em consórcio, avaliadas em três períodos nos diferentes tratamentos de adubação, testemunha (TEST), adubação mineral (ADMI), adubação organomineral (ADOM) e adubação orgânica (ADOR)

\begin{tabular}{|c|c|c|c|c|c|c|}
\hline \multirow{3}{*}{ Tratamentos } & \multicolumn{3}{|c|}{ Aveia preta } & \multicolumn{3}{|l|}{ Azevém } \\
\hline & $1^{\circ}$ Período & $2^{\circ}$ Período & $3^{\circ}$ Período & $1^{\circ}$ Período & $2^{\circ}$ Período & $3^{\circ}$ Período \\
\hline & \multicolumn{6}{|c|}{ Comprimento da parte aérea $(\mathrm{cm})$} \\
\hline TEST & $25,5 \mathrm{~b}$ & $43,7 \mathrm{a}$ & $46,2 \mathrm{a}$ & $13,5 \mathrm{~b}$ & $28,4 \mathrm{c}$ & $49,7 \mathrm{a}$ \\
\hline ADMI & $56,1 \mathrm{a}$ & $54,1 \mathrm{a}$ & $51,0 \mathrm{a}$ & $33,5 \mathrm{a}$ & $46,1 \mathrm{a}$ & $37,7 \mathrm{a}$ \\
\hline ADOM & $60,5 \mathrm{a}$ & $56,5 \mathrm{a}$ & $49,2 \mathrm{a}$ & 39,6 a & $36,3 \mathrm{~b}$ & $42,9 \mathrm{a}$ \\
\hline \multirow[t]{2}{*}{ ADOR } & 56,7 a & $51,9 \mathrm{a}$ & $36,4 \mathrm{a}$ & $34,5 \mathrm{a}$ & $39,7 \mathrm{a}$ & $51,0 \mathrm{a}$ \\
\hline & \multicolumn{6}{|c|}{ Taxa de crescimento $\left.(\mathrm{cm} \mathrm{dia})^{-1}\right)$} \\
\hline TEST & $0,68 \mathrm{~b}$ & $0,72 \mathrm{a}$ & $1,00 \mathrm{a}$ & $0,42 \mathrm{~b}$ & $0,41 \mathrm{c}$ & $1,09 \mathrm{a}$ \\
\hline ADMI & $1,81 \mathrm{a}$ & $0,92 \mathrm{a}$ & $1,12 \mathrm{a}$ & $1,13 \mathrm{a}$ & $0,76 \mathrm{a}$ & $1,10 \mathrm{a}$ \\
\hline ADOM & $1,91 \mathrm{a}$ & $0,97 \mathrm{a}$ & $1,08 \mathrm{a}$ & $1,24 \mathrm{a}$ & $0,57 \mathrm{~b}$ & $0,92 \mathrm{a}$ \\
\hline ADOR & $1,75 \mathrm{a}$ & $0,88 \mathrm{a}$ & $1,06 \mathrm{a}$ & $1,14 \mathrm{a}$ & $0,64 \mathrm{~b}$ & $1,12 \mathrm{a}$ \\
\hline
\end{tabular}

Médias seguidas pela mesma letra na coluna não diferem entre si pelo teste Scott-Knott $(\mathrm{P}>0,05)$.

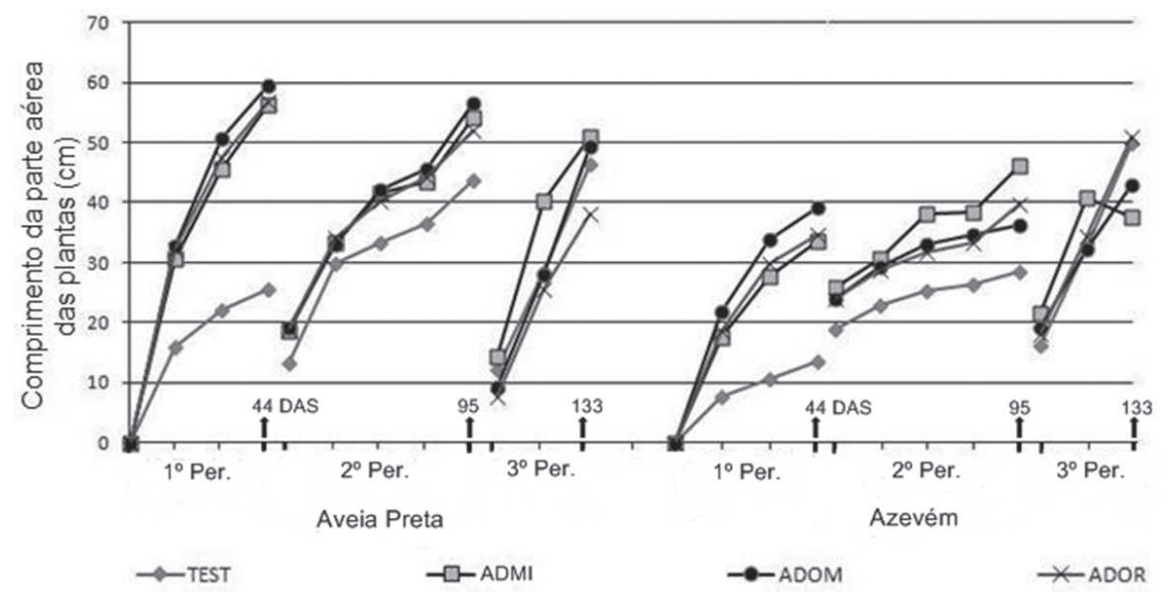

Figura 1. Crescimento de plantas de aveia preta e azevém sob influência dos tratamentos de adubação, testemunha (TEST), adubação mineral (ADMI), adubação organomineral (ADOM) e adubação orgânica (ADOR), avaliadas semanalmente até o momento de cada corte, definido em dias após a semeadura (DAS).

\section{CONCLUSÕES}

O uso do dejeto líquido bovino proporciona produção de massa seca semelhante à dos demais tratamentos de adubação. Assim, é possível o seu uso em substituição total ou parcial da adubação mineral, em consórcio de aveia preta com azevém.

Não há influência das diferentes adubações nas características morfogênicas avaliadas; no entanto, a adubação faz que ocorra maior desenvolvimento inicial de folhas e afilhos e a taxa de crescimento é maior na implantação do consórcio.

\section{REFERÊNCIAS}

Aguinaga AAQ, Carvalho PC de F, Anghinoni I, Pilau A, Aguinaga AJQ \& Gianluppi GDF (2008) Componentes morfológicos e produção de forragem de pastagem de aveia e azevém manejada em diferentes alturas. Revista Brasileira de Zootecnia, 37:1523-1530.
Alvim MJ (2008) Aveia e azevém: forrageiras alternativas para o período da seca. Juiz de Fora, EMBRAPA Gado de Leite. 2p. (Boletim Técnico, 7).

Assmann AL, Pelissari A, Moraes A, Assmann TS, Oliveira EB \& Sandin I (2004) Produção de gado de corte e acúmulo de matéria seca em sistema de integração lavoura-pecuária em presença ou ausência de trevo branco e nitrogênio. Revista Brasileira de Zootecnia, 33:37-44.

Berté LN, Castagnara DD, Bulegon LG, Kuhl JA, Eninger EM, Santos LB, Vendrame JP, Oliveira PSR \& Neres MA (2010) Associação da adubação química e orgânica na produção de milho para silagem no Oeste do Paraná. In: $28^{a}$ Congresso Nacional de Milho e Sorgo, Goiânia. Anais, UNIOESTE. p.961-966.

Bertolote LEM (2009) Sobressemeadura de forrageiras de clima temperado em pastagens tropicais. Dissertação de Mestrado. Universidade Federal Paulista, São Paulo. 84p.

Buriol GA, Estefanel V, Chagas AC de \& Eberhardt D (2007) Clima e vegetação natural do estado do Rio Grande do Sul segundo o diagrama climático de Walter e Lieth. Ciência Florestal, 17:91-100.

Rev. Ceres, Viçosa, v. 61, n.1, p. 112-120, jan/fev, 2014 
CQFS - Comissão de Química e Fertilidade do Solo - RS/SC (2004). Manual de adubação e calagem para os Estados do Rio Grande do Sul e Santa Catarina. 10a ed. Porto Alegre, Evangraf. 394p.

Domingues PF \& Langoni H (2001) Manejo sanitário animal. Rio de Janeiro, EPUB. 210p.

Embrapa - Empresa Brasileira de Pesquisa Agropecuária (2006) Sistema brasileiro de classificação de solos. $2^{\mathrm{a}}$ ed. Rio de Janeiro, Embrapa. 306p.

Freitas AW de P (2000) Dinâmica do perfilhamento em pastagens sob pastejo. Viçosa, Universidade Federal de Viçosa. 21p.

Frizzo A, Rocha MG da, Restle J, Freitas MR, Biscaíno G \& Pilau A (2003) A Produção de forragem e retorno econômico da pastagem de aveia e azevém sob pastejo com bezerras de corte submetidas a níveis de suplementação energética. Revista Brasileira de Zootecnia, 32:632-642.

Macari S, Rocha MG da, Restle J, Pilau A, Freitas FK de \& Neves FP (2006) Avaliação da mistura de cultivares de aveia preta (Avena strigosa Schreb) com azevém (Lolium multiflorum Lam.) sob pastejo. Revista Ciência Rural, 36:910-915.

Macedo LOB (2006) Modernização da pecuária de corte bovina no Brasil e a importância do crédito rural. Informações Econômicas, 36:83-95.

Mullahey JJ, Waller SS \& Moser LE (1991) Defoliation effects on yield and bud and tiller numbers of two sandhills grasses. Journal of Range Management, 44:241-245.

Ohlson O de C, Souza CR de \& Panobianco P (2008) Levantamento da qualidade de sementes de azevém comercializadas no estado do Paraná. ABRATES, 18:18-22.

Piazzetta RG (2007) Produção e comportamento animal em pastagens de aveia e azevém, submetida a diferentes alturas de manejo. Dissertação de Mestrado. Universidade Federal do Paraná, Curitiba. 80p.

Piazzetta RG, Dittrich JR, Alves SJ, Moraes A de, Lustosa SBC, Gazda TL, Melo HA \& Monteiro ALG (2009) Características qualitativas da pastagem de aveia preta e azevém manejada sob diferentes alturas, obtidas pro simulação de pastejo. Archives of Veterinary Science, 14:43-48
Pilau A, Rocha MG da, Restle J, Estivalet R, Neves FP \& Quadros BP de (2004) Recria de novilhas de corte com diferentes níveis de suplementação energética em pastagem de aveia preta e azevém. Revista Brasileira de Zootecnia, 33:2104-2113.

Rocha MG da, Quadros FLF de, Glienke CL, Confortin ACC, Costa VG da \& Rossi GE (2007) Avaliação de espécies forrageiras de inverno na Depressão Central do Rio Grande do Sul. Revista Brasileira de Zootecnia, 36:1990-1999.

Roso C, Restle J, Soares AB \& Andreatta E (2000) Aveia preta, triticale e centeio em mistura com azevém. 1. Dinâmica, produção e qualidade de forragem. Revista Brasileira de Zootecnia, 29:75-84.

Silva F de AS \& Azevedo CAV de (2006) A new version of the Assistat - Statistical Assistance Software. In: World Congress on Computers in Agriculture, Orlando. Anais, American Society of Agricultural and Biological Engineers. p.393-396.

Silveira F de M (2009) Perda de solo, água e nutrientes com aplicação de dejeto líquido bovino em Latossolo franco argilo arenoso sob plantio direto e chuva natural. Dissertação de Mestrado. Universidade Federal do Paraná, Curitiba. 92p.

Steiner F, Czycza RV, Fey R, Zoz T \& Guimarães VF (2009) Acumulo de matéria seca e nitrogênio da aveia preta pela adubação orgânica e mineral. Global Science and Technology, 3:5566

Taiz L \& Zeiger E (2009) Fisiologia Vegetal. $4^{\mathrm{a}}$ ed. Porto Alegre, Artmed. 819p.

Tedesco MJ, Gianello C, Bissani CA, Bohnen H \& Volkweiss SJ (1995) Análise de solo, plantas e outros materiais. $2^{\mathrm{a}}$ ad. Porto Alegre, Universidade Federal do Rio Grande do Sul. 174p.

Valério IP, Carvalho FIF de, Oliveira AC de, Benin G, Maia LC, Silva JAG, Schmidt DM \& Silveira G da (2009) Fatores relacionados à produção e desenvolvimento de afilhos em trigo. Revista Semina, 30:1207-1218. 